\title{
Reduced risk of clinically important deteriorations by ICS in COPD is eosinophil dependent: a pooled post-hoc analysis
}

\author{
Mona Bafadhel ${ }^{1 *}$ D, Dave Singh ${ }^{2}$, Christine Jenkins ${ }^{3}$, Stefan Peterson ${ }^{4}$, Thomas Bengtsson ${ }^{4}$, Peter Wessman ${ }^{5}$ and \\ Malin Fagerås ${ }^{5}$
}

\begin{abstract}
Background: Clinically Important Deterioration (CID) is a novel composite measure to assess treatment effect in chronic obstructive pulmonary disease (COPD). We examined the performance and utility of CID in assessing the effect of inhaled corticosteroids (ICS) in COPD.

Methods: This post-hoc analysis of four budesonide/formoterol (BUD/FORM) studies comprised 3576 symptomatic moderate-to-very-severe COPD patients with a history of exacerbation. Analysis of time to first CID event (exacerbation, deterioration in forced expiratory volume in 1 second $\left[\mathrm{FEV}_{1}\right]$ or worsening St George's Respiratory Questionnaire [SGRQ] score) was completed using Cox proportional hazards models.

Results: The proportion of patients with $\geq 1$ CID in the four studies ranged between 63 and $77 \%$ and $69-84 \%$ with BUD/FORM and FORM, respectively, with an average 25\% reduced risk of CID with BUD/FORM. All components contributed to the CID event rate. Experiencing a CID during the first 3 months was associated with poorer outcomes (lung function, quality of life, symptoms and reliever use) and increased risk of later CID events. The effect of BUD/FORM versus FORM in reducing CID risk was positively associated with the blood eosinophil count.

Conclusions: Our findings suggest that BUD/FORM offers protective effects for CID events compared with FORM alone, with the magnitude of the effect dependent on patients' eosinophil levels. CID may be an important tool for evaluation of treatment effect in a complex, multifaceted, and progressive disease like COPD, and a valuable tool to allow for shorter and smaller future outcome predictive trials in early drug development.
\end{abstract}

Keywords: COPD, Clinically important deterioration (CID), Exacerbations, Budesonide/formoterol, Eosinophils

\section{Background}

Clinical trials in chronic obstructive pulmonary disease (COPD) usually evaluate treatment effect by assessing improvements in individual outcomes such as lung function and quality of life (QoL). Due to the progressive nature of COPD, the mean improvements in clinical outcome are often small and require large and/or lengthy trials. An alternative is to study the effect of treatment using a composite endpoint of disease deterioration. Clinically Important Deteriorations (CID) is a composite endpoint consisting of three components of COPD worsening: COPD exacerbations,

\footnotetext{
* Correspondence: mona.bafadhel@ndm.ox.ac.uk

${ }^{1}$ Respiratory Medicine Unit, Nuffield Department of Medicine, University of Oxford, Old Road Campus, Oxford OX3 7LF, UK

Full list of author information is available at the end of the article
}

deteriorations in lung function (as measured by forced expiratory volume in 1 second $\left[\mathrm{FEV}_{1}\right]$ ), and worsening QoL (as measured by the St George's Respiratory Questionnaire [SGRQ]) [1]. CID has been shown to predict long-term outcomes, including mortality [2].

Studies using CID have focused primarily on long-acting bronchodilator effects [1,3-6], mostly in COPD populations without increased exacerbation risk, often leading to a predominance of CID events triggered by lung function deteriorations, and a relatively small contribution of exacerbations to the composite index. Recently, higher blood eosinophil counts have been shown to be associated with increased exacerbation risk in COPD patients not treated with inhaled corticosteroids (ICS) $[7,8]$. The relationship between blood eosinophils and risk of CID is unknown.

(C) The Author(s). 2020 Open Access This article is distributed under the terms of the Creative Commons Attribution 4.0 International License (http://creativecommons.org/licenses/by/4.0/), which permits unrestricted use, distribution, and 
In this post-hoc analysis of four randomized clinical trials (SUN [9], SHINE [10], US3 [11] and RISE [12]), we assessed the effect of an ICS/long-acting $\beta_{2}$-agonist (LABA) combination, budesonide/formoterol (BUD/ FORM), versus the LABA mono-component alone, on the risk of CID in symptomatic patients with COPD and a history of exacerbations. We evaluated the protective effect of ICS on CID, as well as the predictive properties of peripheral blood eosinophil count and other clinical characteristics. We also assessed the prognostic properties of a CID event on the risk of further events and future deterioration in lung function and quality of life, and how this might impact on future clinical trial design.

\section{Methods}

\section{Study designs and population}

Details of the study designs have been published previously [9-12]. Briefly, SUN [9] and US3 [11] were 52week, and SHINE [10] and RISE [12] were 26-week, multicentre, randomized, double-blind, double-dummy, parallel-group studies. Details regarding study designs can be found in the supplement (Additional file 1: Table S1). Here, we report the results for analyses comparing the twice daily (bid) BUD/FORM 160/4.5 $\mu$ g pressurized metered dose inhaler (pMDI) and FORM $4.5 \mu \mathrm{g}$ dry powder inhaler (DPI) treatment arms, a comparison included in all four studies, in a total of 3576 patients.

Patients were aged $\geq 40$ years with a current clinical diagnosis of COPD and were current or former smokers, with a pack-year history of $>10$ years. All patients had confirmed airflow obstruction and a history of $\geq 1$ exacerbation. In SUN, SHINE and US3, all current COPD medications, with the exception of ICS, were discontinued during the run-in period. In RISE, all patients were treated with BUD/FORM 160/4.5 $\mu \mathrm{g}$ bid during run-in. Albuterol (salbutamol) was provided for as-needed use.

\section{Procedures}

Detailed demographic data were collected at baseline. All patients had lung function and health status recorded at scheduled visits (Additional file 1: Table S1). Exacerbations were defined per protocol as worsening of COPD that required treatment with a course of systemic corticosteroids with or without antibiotics, or required hospitalization. A differential full blood count was collected at study entry, except in the RISE trial.

\section{CID definition}

A CID event was defined as the occurrence of any of the following individual components: $\mathrm{a} \geq 100-\mathrm{mL}$ decrease from baseline in pre-dose $F E V_{1}, a \geq 4$-unit increase from baseline in SGRQ total score, or the start of a moderateto-severe COPD exacerbation after the first dose of study medication.

\section{Statistical analyses}

Studies were analysed using the full analysis population. Analysis was performed for each study separately, unless otherwise indicated. Analyses were completed until endof-study and on censored data at 3 months (Day 90) and 6 months (Day 180).

Each first CID was identified by the first occurrence of any CID component, with the day of onset set as the onset day of that event. Patients with no CID events were censored at the last study day. For analysis of individual components, the first occurrence of the component event was used, independent of whether this coincided with the first CID or not.

Time to first CID was displayed using Kaplan-Meier plots, from which median event times were determined. Time to first CID was analysed using Cox proportional hazards models adjusting for treatment and country. BUD treatment effects were expressed as hazard ratios (HR) between BUD/FORM and FORM alone, with 95\% confidence intervals and two-sided $p$-values. To test the assumption of proportional hazards (heterogeneous effect over time) assumed in the Cox model, models adjusting for treatment, country and interaction treatment by logarithm of the day of event were used.

Subgroup analyses of time to first CID were performed based on baseline characteristics, including smoking status, long-acting muscarinic antagonists (LAMA) and ICS use prior to study entry, baseline lung function, exacerbation history, age, gender, and total SGRQ score (Additional file 1: Figure S1). The analyses were performed using Cox proportional hazards models adjusting for treatment, strata and treatment by strata interaction.

To explore the predictive value of an early CID event, patients were divided based on occurrence of a first CID within 3 months (84 days; CID+), or not (CID-). For each stratum and study, the mean change from baseline over the full study period for $\mathrm{FEV}_{1}$ and SGRQ was constructed using last value carried forward to impute missing data. Mean changes from baseline were constructed for total daily rescue use and total symptoms (sum of Breathlessness, Cough, and Sputum Scale [BCSS৫] scores) based on weekly means of daily observations.

The number of CID events per patient was defined as all observed CID events, in which any CID starting or ending within 7 days would be counted as one event. Analysis of the number of CID events used negative binomial modelling adjusting for treatment and country and using the natural logarithm of the time in study as offset. Estimated event rates were annualized and treatment effect was expressed as a relative rate ratio (RR).

The prognostic and predictive properties of baseline blood eosinophil counts were investigated using a cumulative approach that utilized cut-off levels covering the main part of the eosinophil spectra 
Table 1 Demographic and baseline characteristics by study (budesonide/formoterol 160/4.5 $\mu \mathrm{g}$ and formoterol $4.5 \mu \mathrm{g}$ arms only)

\begin{tabular}{|c|c|c|c|c|}
\hline Characteristic & SUN $(n=989)$ & SHINE $(n=561)$ & US3 $(n=807)$ & RISE $(n=1219)$ \\
\hline Age, years & $63.0(40-88)$ & $63.3(41-89)$ & $63.1(40-87)$ & $63.5(40-87)$ \\
\hline Male, n (\%) & $631(63.8)$ & $374(66.7)$ & $490(60.7)$ & $698(57.3)$ \\
\hline Female, n (\%) & $358(36.2)$ & $187(33.3)$ & $317(39.3)$ & $521(42.7)$ \\
\hline \multicolumn{5}{|l|}{ Race, n (\%) } \\
\hline White & $914(92.4)$ & $523(93.2)$ & $667(82.8)$ & $1119(91.8)$ \\
\hline Black & $23(2.3)$ & $20(3.6)$ & $33(4.1)$ & $39(3.2)$ \\
\hline Asian & $5(0.5)$ & $2(0.4)$ & $10(1.2)$ & $17(1.4)$ \\
\hline Other & $47(4.8)$ & $16(2.9)$ & $96(11.9)$ & $44(3.6)$ \\
\hline Former smoker, n (\%) & $573(57.9)$ & $319(56.9)$ & $516(63.9)$ & $655(53.7)$ \\
\hline Current smoker, n (\%) & $416(42.1)$ & $242(43.1)$ & $291(36.1)$ & $564(46.3)$ \\
\hline No. exacerbations in previous year & $1.8(1-13)$ & $1.6(0-8)$ & $1.7(1-12)$ & $1.4(1-7)$ \\
\hline Post-FEV $1, \mathrm{~L}$ & $1.18(0.35-3.26)$ & $1.20(0.30-3.29)$ & $1.11(0.34-2.96)$ & $1.38(0.34-3.6)$ \\
\hline Post-FEV $1, \%$ predicted & $38.9(13-92)$ & $39.3(10-103)$ & $37.7(12-77)$ & $48.7(16-78)$ \\
\hline $\mathrm{FEV}_{1} / \mathrm{FVC}$ ratio & $0.49(0.20-0.85)$ & $0.48(0.20-0.82)$ & $0.47(0.16-1.00)$ & $0.49(0.19-0.75)$ \\
\hline Eosinophils, $\times 10^{9} / \mathrm{L}$, geometric mean (range) & $0.18(0.01-1.47)$ & $0.18(0.01-1.01)$ & $0.13(0.01-2.51)$ & $N / A^{a}$ \\
\hline SGRQ total score & $54.9(7-100)$ & $54.9(14-100)$ & $57.5(6-99)$ & $46.7(0-97)$ \\
\hline
\end{tabular}

Data presented as mean (range) unless otherwise stated

aLaboratory data was not assessed in RISE; therefore, no baseline data are available for eosinophils

FEV 1 Forced expiratory volume in $1 \mathrm{~s}$, FVC Forced vital capacity, N/A Not applicable, SGRQ St George's Respiratory Questionnaire

For full baseline characteristics, see Additional file 1: Table S2

Table 2 Summary of events and characteristics by study

\begin{tabular}{|c|c|c|c|c|c|c|c|c|}
\hline & \multicolumn{2}{|l|}{ SUN $(n=989)$} & \multicolumn{2}{|l|}{ SHINE $(n=561)$} & \multicolumn{2}{|l|}{ US3 ( $n=807)$} & \multicolumn{2}{|l|}{$\operatorname{RISE}(n=1219)$} \\
\hline & $\begin{array}{l}\text { BUD/FORM 160/ } \\
4.5 \mu \mathrm{g} \text { bid }(n= \\
494)\end{array}$ & $\begin{array}{l}\text { FORM } \\
4.5 \mu \mathrm{g} \text { bid } \\
(n=495)\end{array}$ & $\begin{array}{l}\text { BUD/FORM 160/ } \\
4.5 \mu \mathrm{g} \text { bid }(n= \\
277)\end{array}$ & $\begin{array}{l}\text { FORM } \\
4.5 \mu \mathrm{g} \text { bid } \\
(n=284) \\
\end{array}$ & $\begin{array}{l}\text { BUD/FORM 160/ } \\
4.5 \mu \mathrm{g} \text { bid }(n= \\
404)\end{array}$ & $\begin{array}{l}\text { FORM } \\
4.5 \mu \mathrm{g} \text { bid } \\
(n=403)\end{array}$ & $\begin{array}{l}\text { BUD/FORM 160/ } \\
4.5 \mu \mathrm{g} \text { bid }(n= \\
606)\end{array}$ & $\begin{array}{l}\text { FORM } \\
4.5 \mu \mathrm{g} \text { bid } \\
(n=613) \\
\end{array}$ \\
\hline Any CID & $343(69.4)$ & $360(72.7)$ & $173(62.5)$ & $196(69.0)$ & $280(69.3)$ & $305(75.7)$ & $468(77.2)$ & $517(84.3)$ \\
\hline \multicolumn{9}{|l|}{ Subtypes of first CID } \\
\hline $\begin{array}{l}\text { Exacerbation } \\
\text { alone }\end{array}$ & $81(23.6)$ & $96(26.7)$ & $47(27.2)$ & $47(24.0)$ & $114(40.7)$ & $126(41.3)$ & $61(13.0)$ & $74(14.3)$ \\
\hline $\mathrm{FEV}_{1}$ event alone & $120(35.0)$ & $112(31.1)$ & $62(35.8)$ & $59(30.1)$ & $90(32.1)$ & $86(28.2)$ & $172(36.8)$ & $174(33.7)$ \\
\hline SGRQ alone & $116(33.8)$ & $112(31.1)$ & $49(28.3)$ & $76(38.8)$ & $61(21.8)$ & $75(24.6)$ & $172(36.8)$ & $171(33.1)$ \\
\hline $\begin{array}{l}\text { Exacerbation + } \\
\text { FEV } 1\end{array}$ & $3(0.9)$ & $5(1.4)$ & $0(0.0)$ & $2(1.0)$ & $6(2.1)$ & $8(2.6)$ & $5(1.1)$ & $7(1.4)$ \\
\hline $\begin{array}{l}\text { Exacerbation + } \\
\text { SGRQ }\end{array}$ & $3(0.9)$ & $4(1.1)$ & $4(2.3)$ & $2(1.0)$ & $1(0.4)$ & $4(1.3)$ & $6(1.3)$ & $7(1.4)$ \\
\hline $\mathrm{FEV}_{1}+\mathrm{SGRQ}$ & $20(5.8)$ & $30(8.3)$ & $10(5.8)$ & $10(5.1)$ & $7(2.5)$ & $5(1.6)$ & $51(10.9)$ & 79 (15.3) \\
\hline $\begin{array}{l}\text { Exacerbation + } \\
\mathrm{FEV}_{1}+\mathrm{SGRQ}\end{array}$ & $0(0)$ & $1(0.3)$ & $1(0.6)$ & $0(0)$ & $1(0.4)$ & $1(0.3)$ & $1(0.2)$ & $5(1.0)$ \\
\hline \multicolumn{9}{|c|}{ Individual components } \\
\hline Exacerbations & $152(30.8)$ & $177(35.8)$ & $69(24.9)$ & $78(27.5)$ & $169(41.8)$ & $182(45.2)$ & $151(24.9)$ & $181(29.5)$ \\
\hline $\mathrm{FEV}_{1}$ events & 196 (39.7) & $212(42.8)$ & $84(30.3)$ & $100(35.2)$ & 135 (33.4) & $161(40.0)$ & $289(47.7)$ & $344(56.1)$ \\
\hline SGRQ events & 188 (38.1) & $202(40.8)$ & 81 (29.2) & $116(40.8)$ & $143(35.4)$ & $164(40.7)$ & $312(51.5)$ & $357(58.2)$ \\
\hline
\end{tabular}

Event rates in percentage of total number of patients; CID sub-events in percentage of total CID events

The rows with individual components (exacerbations, FEV ${ }_{1}$ events, SGRQ events) describe events as independent variables, whereas the subtypes of first CID events describe the variable/combination occurring first within a patient. Bid, twice daily; BUD Budesonide, CID Clinically Important Deterioration, FEV ${ }_{1}$ Forced expiratory volume in $1 \mathrm{~s}$, FORM Formoterol, SGRQ St George's Respiratory Questionnaire 


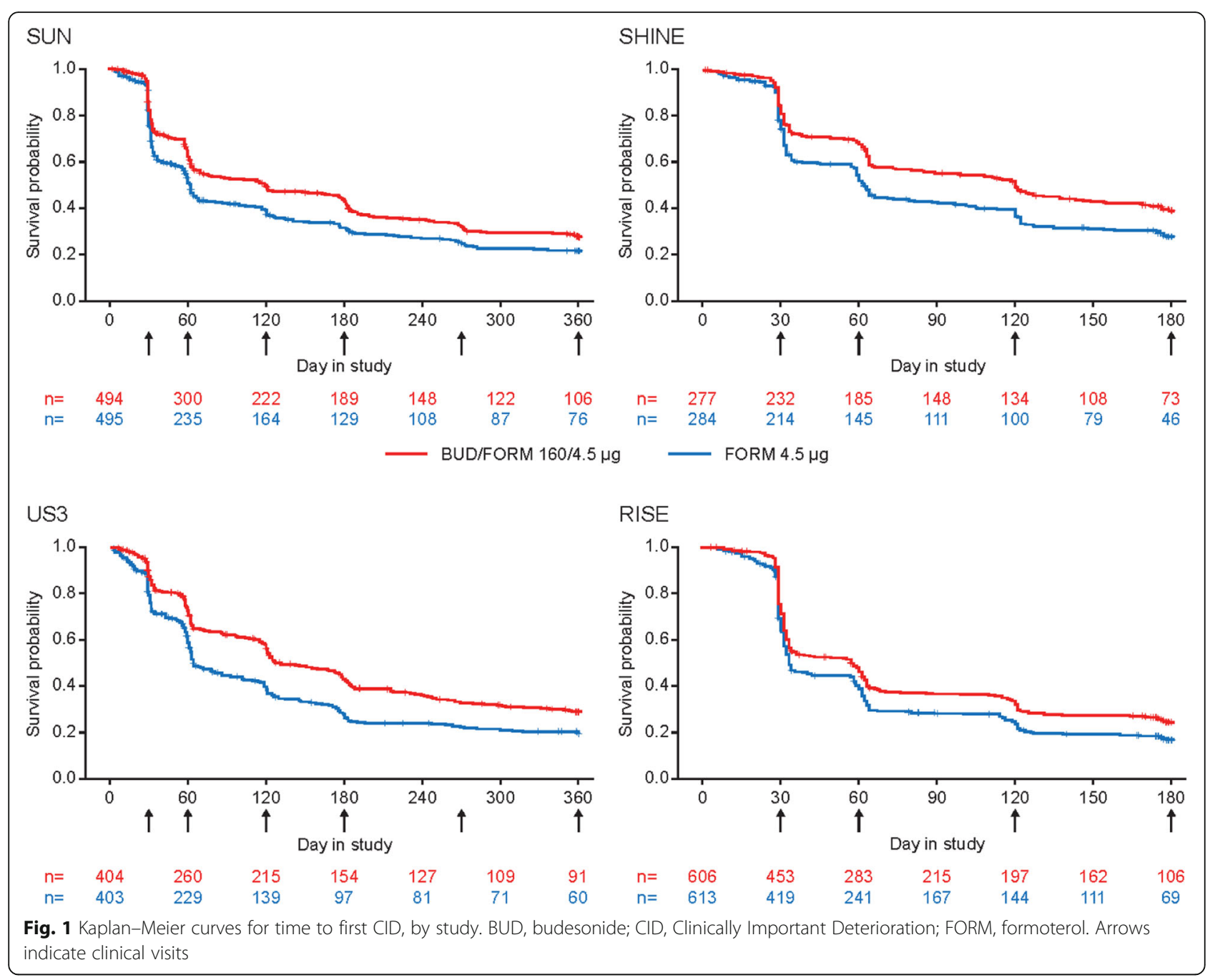

$\left(0.07-0.35 \times 10^{9} / \mathrm{L}\right.$ with a 0.01 step). For each cut-off level, patients were divided into a lower and higher stratum ( $\leq$ cut-off and > cut-off, respectively); the analyses from different cut-offs were combined to determine the relationship between eosinophil levels and CID events. The SUN, SHINE, and US3 studies were pooled for analyses, using Cox proportional hazards models adjusting for treatment and stratified by study. HRs from each analysis were plotted versus the cut-off level, showing the change in effect when extending the eosinophil range upwards (lower stratum, left to right) or downwards (upper stratum, right to left). The HR from the analysis of the full population is indicated as a reference to show the convergence point of the curves. A pooled analysis was performed using a negative binomial model for the number of CID events by baseline eosinophil level, with treatment and study as fixed factors.

\section{Results}

Demographic and baseline characteristics were similar between studies (Table 1 and Additional file 1: Table S2), and were similar between patients who did and did not experience a CID during the studies (Additional file 1: Table S3).

\section{CID events}

The proportion of patients experiencing $\geq 1$ CID over the study duration ranged from 63 to $77 \%$ and $69-84 \%$ in the BUD/FORM and FORM arms, respectively, across the four studies. The majority of CID events were triggered by one criterion only, with $\leq 15 \%$ of the first CID event fulfilling more than one criterion. Events fulfilling the $\mathrm{FEV}_{1}$ criterion accounted for $35-50 \%$ of the first CID events, SGRQ criterion 26-50\%, and exacerbation criterion $17-45 \%$ in the studies (Table 2). Due to the definition of CID, many events were clustered around the clinical visits (Fig. 1). 


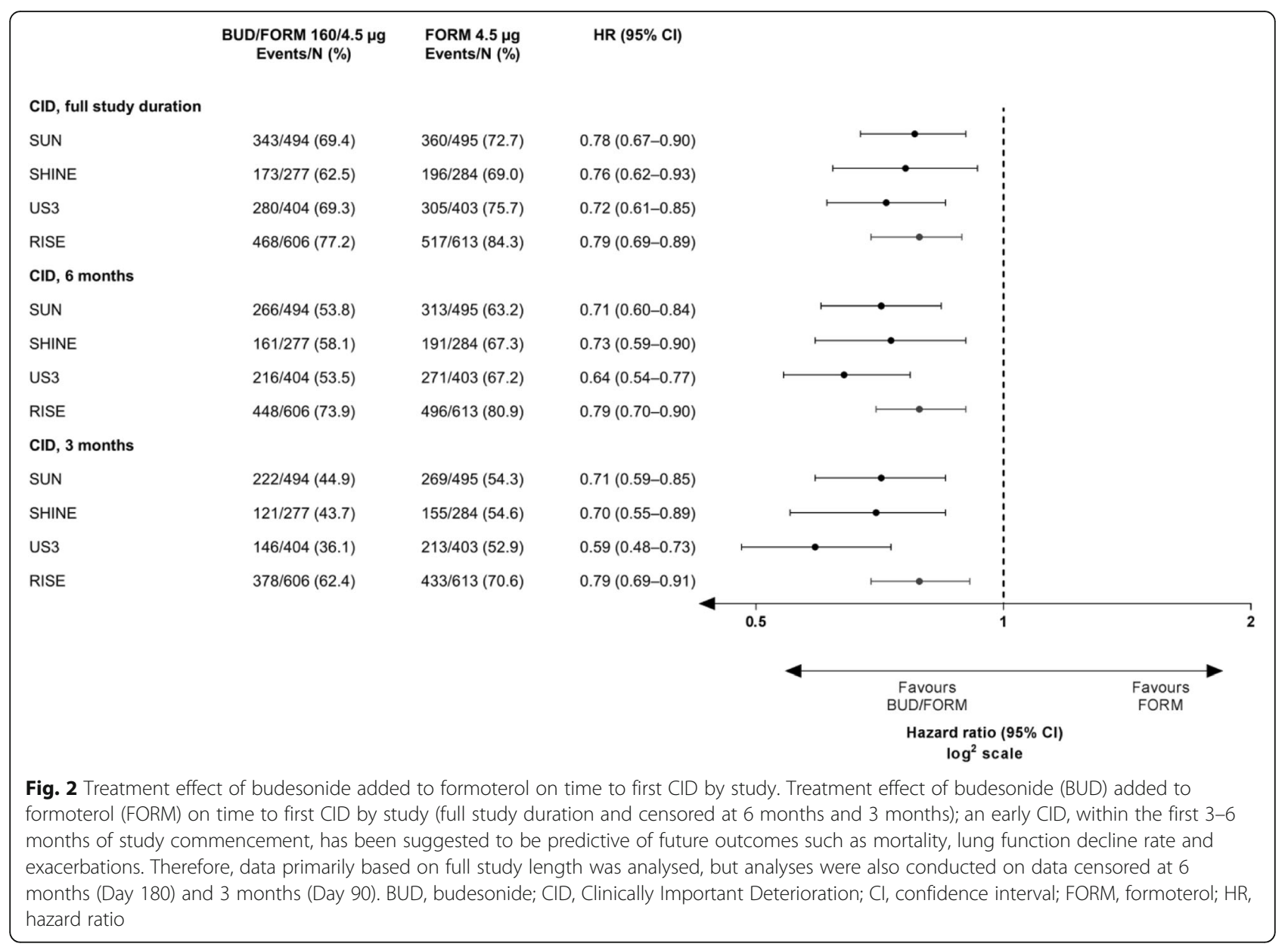

\section{Treatment effect of BUD/FORM}

Treatment with BUD/FORM significantly prolonged the time to first CID and reduced the risk of CID by $21-28 \%$ versus FORM alone in all four studies $(p<0.001$, Fig. 2). The majority of patients experienced their first CID event early, with median time to first CID of 119-127 days (BUD/FORM) and 62-64 days (FORM) in SUN, SHINE and US3, and 57 days (BUD/FORM) and 33 days (FORM) in RISE (Fig. 1). In all studies, the estimated treatment effect for the individual components were all in favour of BUD/FORM, with estimated risk reductions ranging from 15 to $23 \%$ for $\mathrm{FEV}_{1}, 14-39 \%$ for SGRQ deteriorations and 20-24\% for exacerbations (Additional file 1: Figure S2). Due to fewer events, and thereby lower power, risk reductions did not always reach statistical significance for the individual components.

Tests of the assumptions of proportional hazards for CID indicated significant deviation in the 12month SUN and US3 studies $(p=0.006$ and $p=0.001$, respectively), but not in the 6-month SHINE and RISE studies ( $p=0.096$ and $p=0.570$, respectively) (Additional file 1: Table S4). This would indicate a non-constant treatment effect over the study period; however, the Kaplan-Meier curves do not cross in either of the studies.

Data analysis with values censored at 3 and 6 months was performed. BUD/FORM reduced the risk of CID between 21 and $41 \%$ over 3 months and between 21 and $36 \%$ over 6 months versus FORM (Fig. 2). Assessment over the shorter study durations demonstrated improved proportionality of the hazards for both CID and the individual components (Additional file 1: Table S4).

\section{Early CID versus later CID outcomes}

In the pooled treatment arms, $43-67 \%$ of patients experienced $\geq 1$ CID during the first 3 months, termed early CID (CID+). CID+ patients were more likely to experience a further CID after the first 3 months compared with patients without an early CID event (CID-) (Fig. 3).

An early and sustained improvement from baseline in FEV $_{1}$ and SGRQ was observed in CID- patients, with a mean change in $\mathrm{FEV}_{1}$ ranging $91-159 \mathrm{~mL}$ and a mean change in SGRQ score ranging from -9.1 to -5.2 units between studies (Fig. 4a and b). In CID+ patients, FEV and SGRQ remained similar to baseline values or worsened over the study, with a change from baseline ranging 


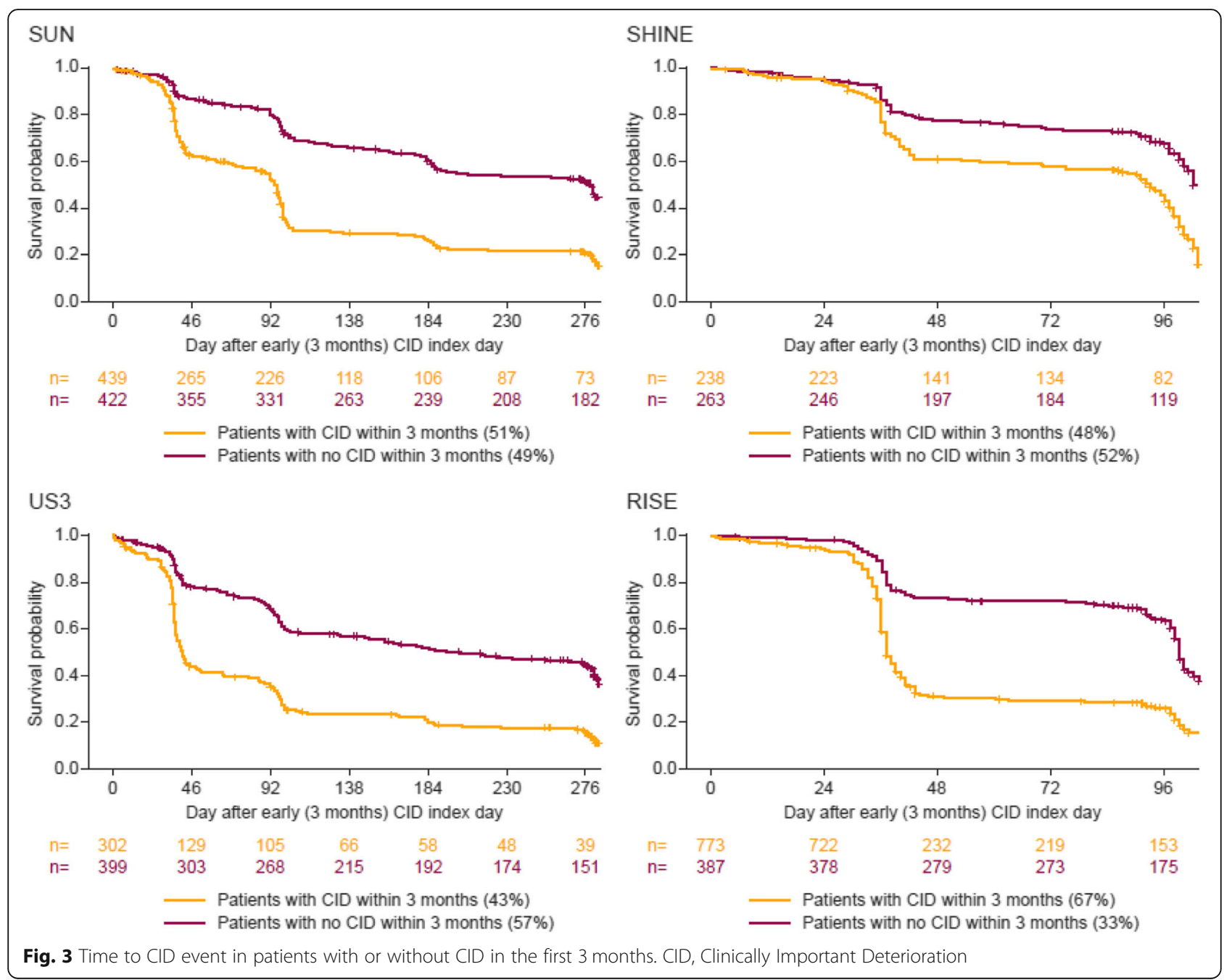

from -56 to $4 \mathrm{~mL}$ in $\mathrm{FEV}_{1}$ and from -1.6 to 2.3 units in SGRQ score (Fig. 4a and b). Compared with baseline, the mean weekly reliever use was reduced in both CID+ and CID- patients, except in RISE (Fig. 4c). Mean weekly total symptom score improved in both CID- and CID+ patients, but to a larger extent in CID- (Fig. 4d).

\section{Effect of blood eosinophils}

Baseline blood eosinophil count was available from 2286 patients in SUN, SHINE and US3. When analysing subgroups of lower and upper eosinophil strata, defined based on baseline eosinophil levels below (lower eosinophil stratum) and above (upper eosinophil stratum) a range of cut-offs, the treatment effects (HR) on CID events between BUD/FORM and FORM were consistently greater for patients in the upper stratum compared with patients in the lower stratum (Fig. 5). The $0.10 \times$ $10^{9} / \mathrm{L}$ eosinophil cut-off corresponded to a mean HR for BUD/FORM versus FORM of 0.67 (95\% CI: $0.60-0.75$ ) for the upper stratum population (above $0.10 \times 10^{9} / \mathrm{L}$ eosinophils, $75 \%$ of patients) while no reduced CID risk of BUD/FORM (HR 0.97; 95\% CI: 0.80-1.18) was apparent in the lower stratum (at or below $0.10 \times 10^{9} / \mathrm{L}$ eosinophils, $25 \%$ of patients). The $0.30 \times 10^{9} / \mathrm{L}$ eosinophil cutoff corresponded to a mean HR for BUD/FORM versus FORM of 0.57 (95\% CI: 0.46-0.71) in the upper stratum ( $20 \%$ of patients) compared to a HR of 0.79 (95\% CI: $0.71-$ 0.88 in the lower stratum. A similar relationship between baseline eosinophil counts (upper and lower strata) and treatment effect was observed for the individual components of CID (Additional file 1: Figure S3). A selected range of eosinophil cut-offs and corresponding HRs are presented in Table 3. Eosinophil stratum censored data at 3 and 6 months are presented in the supplement (Additional file 1: Figure S4; Additional file 1: Tables S5 and S6).

\section{Annualized rate of CID}

The proportion of patients who experienced $>1$ CID over the study period ranged from 33 to $65 \%$ (Additional file 1: Figure S5), and the mean number of CID events per patient 


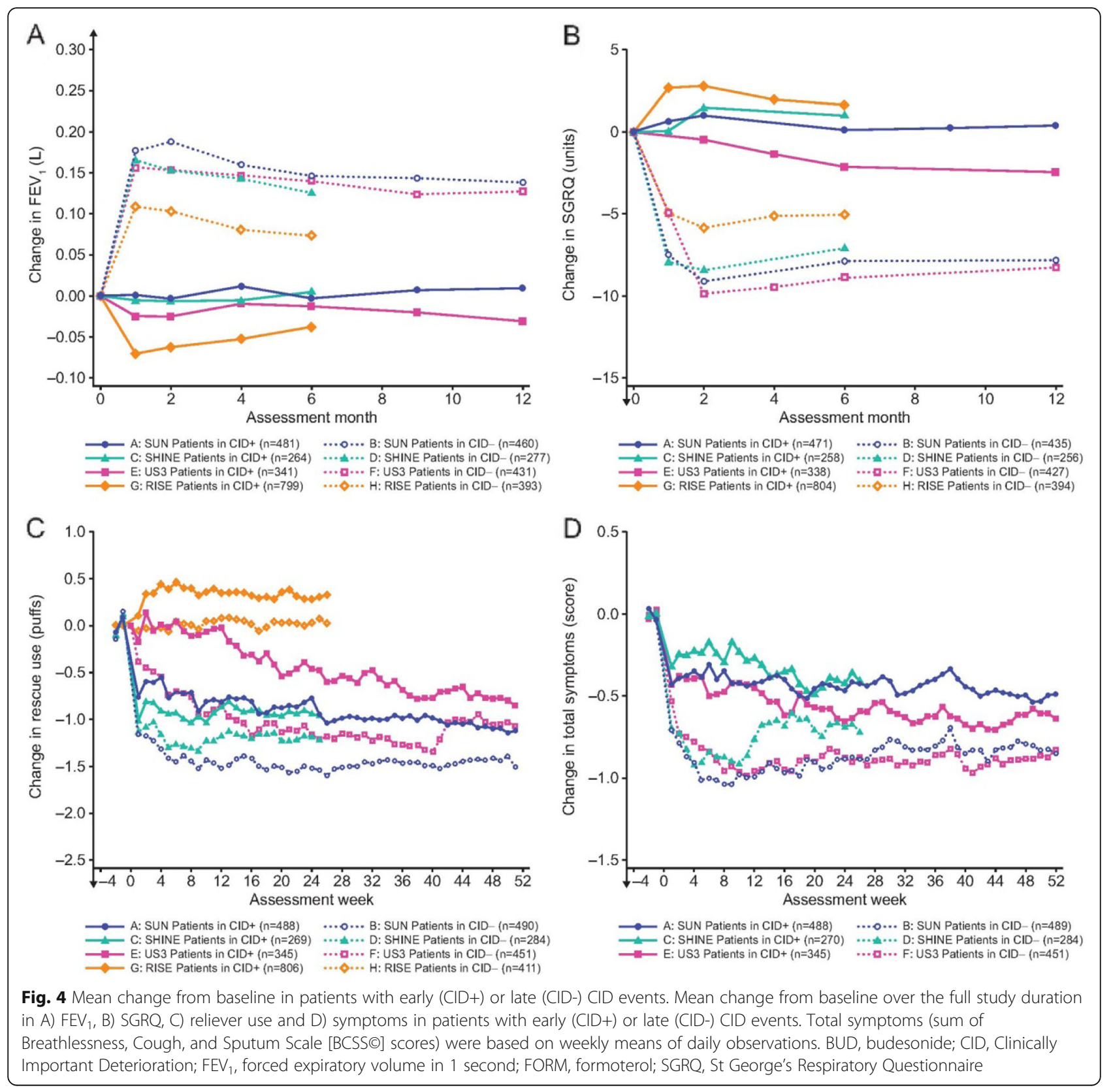

per year ranged from 2.05-4.27 in the BUD/FORM arm and 2.85-5.04 in the FORM arm in the four studies. The rate ratio for BUD/FORM versus FORM indicated a reduction of $15-28 \%$ in the four studies $(p \leq 0.001$, Additional file 1: Figure S6). A similar size of treatment effect on the individual components was observed (Additional file 1: Figure S6). The relationship between baseline eosinophil levels and the RR, based on analysis of total number of CID, showed a reduced RR at every eosinophil level in the upper stratum compared with the lower stratum (Additional file 1: Figure S7). In patients with blood eosinophil counts $<0.10 \times 10^{9} / \mathrm{L}$, low-to-no treatment effect was observed $(\mathrm{RR}=0.87$; 95\% CI: 0.73-1.05).

\section{Discussion}

This analysis demonstrates a protective effect of ICS on CID, with a risk reduction of approximately $25 \%$ across the four studies. ICS had a protective effect on all individual CID components, indicating that the benefit offered by BUD extends beyond the effect on exacerbations, and includes prevention of deteriorations in lung function and QoL. This contrasts with the modest effect of ICS when assessing improvements in $\mathrm{FEV}_{1}$ and SGRQ previously reported with ICS [13], suggesting that ICS in COPD are primarily preventive and protective, rather than to induce improvements in lung function and QoL only. Patients who experienced a CID within 

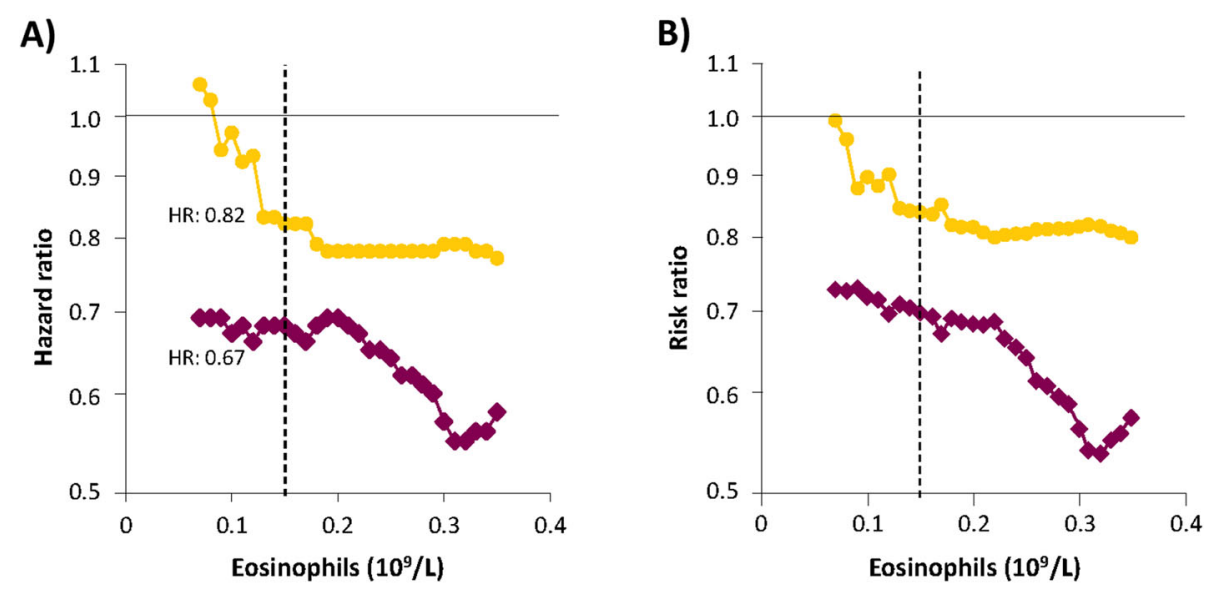

$\rightarrow-$ Lower stratum $\rightarrow$ Upper stratum

Fig. 5 Effect size by eosinophil cut-off in pooled analysis of SUN, SHINE and US3. Effect size by eosinophil cut-off in pooled analysis of SUN, SHINE and US3 for A) time to first CID event (hazard ratio [HR]) and B) number of events (risk ratio [RR]). Note: The solid line represents HR or RR of 1.0, while the dotted line represents treatment effect for the whole population. At each individual eosinophil count plotted, HR is calculated for the lower stratum in yellow (indicating the mean HR for all patients with an eosinophil count at or below cut-off) and the upper stratum in purple (indicating the mean HR for all patients above the cut-off). Example HR presented for cut-off at $0.15 \times 10^{9} / \mathrm{L}$ (vertical dotted line). The eosinophil range used here is narrower than the actual eosinophil range. There were a relatively small number of patients with higher values at a cut-off of $0.36 \times 10^{9} / \mathrm{L}$, thus relevant analyses cannot be obtained in the upper strata if it were extended beyond this cut off

the first 3 months had an increased risk of experiencing additional events later, and had a poorer outcome with regard to lung function decline, worsened QoL, increased reliever use and symptoms over the study period compared with patients who did not experience a CID within the first 3 months. This suggests that CID events are prognostic of longer-term clinical outcomes in patients at increased risk of exacerbations.

The reduced risk of CID by BUD/FORM versus FORM alone was associated with baseline blood eosinophil counts, with a larger effect observed with higher eosinophil counts. These results add to the evidence showing that blood eosinophils are a biomarker which identify patients most likely to benefit from ICS treatment through prevention of exacerbations $[7,8,14]$. Our data also support the use of eosinophils as a predictive biomarker for ICS effects on lung function and QoL, as previously reported in the INCONTROL study, in which higher eosinophil counts were associated with ICSinduced improvements in $\mathrm{FEV}_{1}$ and SGRQ scores [7]. Moreover, our data suggest that in patients with low blood eosinophils counts $\left(<0.1 \times 10^{9}\right.$ cells $\left./ \mathrm{L}\right)$, the treatment benefit of BUD/FORM versus FORM - and thus the effect of BUD - is poor to minimal. This indicates a subpopulation of COPD patients who should be both considered for exclusion from clinical trials investigating the effect of ICS, and in whom there is an unlikely benefit clinically and a potential increase in harm [7, 14]. These findings align with the recommendations in the updated GOLD 2019 report [15]. The data also show that, in patients with an eosinophil count $\geq 0.1 \times 10^{9}$ cells/L, corresponding to approximately $75 \%$ of the study population, BUD reduced the risk of CID by at least $33 \%$, with increasingly beneficial effect with higher eosinophil levels.

Most previous publications on CID in COPD evaluate the effect of bronchodilators [1,3-6] and, due to the study designs and patient populations, $\mathrm{FEV}_{1}$ deterioration is then the most frequent event type reported [9-12]. If $\mathrm{FEV}_{1}$ is assessed at all visits, but not SGRQ, this can give an imbalance in the number of individual CID components. When designing new studies with CID as an outcome measure, our findings suggest that study visits should be spread out evenly during the study period, and $\mathrm{FEV}_{1}$ and SGRQ should always be assessed simultaneously. In our study we found that the individual CID components contributed substantially to the total CID rate, with the effects of BUD/FORM versus FORM on CID generally reflected by the individual components. A post-hoc analysis of the FLAME study [16], in which the effect of indacaterol/glycopyrronium versus salmeterol/ fluticasone on CID was evaluated in patients with an exacerbation history, showed a greater effect of the dual bronchodilator on CID prevention. The largest effect was seen on $\mathrm{FEV}_{1}$ deteriorations, consistent with other bronchodilator studies [1, 3-6]. Ideally, all components should contribute to the treatment effect in the same direction and with a similar weight. Longer duration studies often record $\mathrm{FEV}_{1}$ and SGRQ more frequently near the beginning; this can result in a higher number of $\mathrm{FEV}_{1}$ and SGRQ events recorded 
Table 3 Analysis of time to first CID by selected eosinophil cut-offs (pooled analysis; full study duration)

\begin{tabular}{|c|c|c|c|c|c|c|}
\hline \multirow{2}{*}{$\begin{array}{l}\text { Cut-off, } \\
\times 10^{9} / \mathrm{L}(\% \\
\leq)\end{array}$} & \multicolumn{3}{|l|}{ Lower stratum } & \multicolumn{3}{|l|}{ Upper stratum } \\
\hline & BUD/FORM 160/4.5 $\mu \mathrm{g}$ bid & $\begin{array}{l}\text { FORM } \\
4.5 \mu \mathrm{g} \text { bid }\end{array}$ & $\mathrm{HR}(95 \% \mathrm{Cl})$ & BUD/FORM 160/4.5 $\mu \mathrm{g}$ bid & $\begin{array}{l}\text { FORM } \\
4.5 \mu \mathrm{g} \text { bid }\end{array}$ & $\mathrm{HR}(95 \% \mathrm{Cl})$ \\
\hline $0.10(25.2)$ & $201 / 285(70.5)$ & 199/291 (68.4) & $0.97(0.80-1.18)$ & $569 / 857(66.4)$ & $633 / 853(74.2)$ & $0.67(0.60-0.75)$ \\
\hline $0.15(44.8)$ & $350 / 503(69.6)$ & $373 / 520(71.7)$ & $0.82(0.71-0.95)$ & $420 / 639(65.7)$ & 459/624 (73.6) & $0.68(0.59-0.77)$ \\
\hline $0.20(60.9)$ & $466 / 675(69.0)$ & $519 / 718(72.3)$ & $0.78(0.69-0.88)$ & $304 / 467(65.1)$ & $313 / 426(73.5)$ & $0.69(0.59-0.80)$ \\
\hline $0.25(73.1)$ & $560 / 818(68.5)$ & $613 / 852(71.9)$ & $0.78(0.69-0.87)$ & 210/324 (64.8) & 219/292 (75.0) & $0.64(0.53-0.78)$ \\
\hline $0.30(79.9)$ & 616/896 (68.8) & 670/931 (72.0) & $0.79(0.71-0.88)$ & $154 / 246(62.6)$ & $162 / 213(76.1)$ & $0.57(0.46-0.71)$ \\
\hline $0.35(85.2)$ & 659/965 (68.3) & $708 / 983(72.0)$ & $0.77(0.69-0.86)$ & $111 / 177(62.7)$ & $124 / 161(77.0)$ & $0.58(0.45-0.75)$ \\
\hline
\end{tabular}

Numbers shown: event/total (\%)

bid, twice daily; BUD Budesonide, CID Clinically Important Deterioration, CI Confidence interval, FORM Formoterol, HR Hazard ratio

early on and more exacerbations thereby being censored by such events regarding first CID.

An early CID within the first 3-6 months of study commencement has been suggested to be predictive of future outcomes such as mortality, lung function deterioration and exacerbations [15]. Here, we confirm the potential prognostic value of an early CID by showing that a CID during the first 3 months increases the likelihood of experiencing additional disease deteriorations in the following 3-9 months. In previous reports evaluating treatment effect on CID, only the first event occurrence has been captured with time-to-first analyses [1, 3-6]. Our findings show that a significant number of patients experience a CID (50\% already at 4 months), suggesting that studies with shorter duration could focus on time-to-first CID analysis, and that longer studies could concentrate on the total number of CID events. Altogether, this suggests that CID could be an important tool during early clinical drug development, allowing shorter and/or smaller trials compared with traditional exacerbation or lung function trials, while also being predictive of future outcomes. CID offers increased development efficiency, while exposing fewer patients to novel compounds with as yet unknown safety profiles.

In conclusion, the addition of BUD to FORM reduced the risk and number of CID in moderate-tosevere COPD patients; an effect on exacerbations was seen as well as an effect on deteriorations in lung function and QoL, and benefits were apparent for patients with blood eosinophils above $0.1 \times 10^{9} / \mathrm{L}$. This indicates that treatment with BUD offers important preventive and protective effects on several important aspects of COPD. Our upper and lower stratum analytical approaches highlight the importance of blood eosinophils to identify patients for ICS treatment with relevance to studies and study design exploring the effect of ICS in COPD. We suggest that CID is a valuable tool for evaluation of treatment effects that address several aspects of a complex, multifaceted and progressive disease like COPD, and could allow for shorter and smaller trials predictive of future outcome for early drug development.

\section{Supplementary information}

Supplementary information accompanies this paper at https://doi.org/10. 1186/s12931-020-1280-y.

Additional file 1 : Table S1. Visit and assessment schedule by study. Table S2. Demographic and baseline characteristics by study

(budesonide/formoterol 160/4.5 $\mu \mathrm{g}$ and formoterol $4.5 \mu \mathrm{g}$ arms only).

Table S3. Demographic and baseline characteristics by occurrence of CID event by study (budesonide/formoterol 160/4.5 $\mu \mathrm{g}$ and formoterol $4.5 \mu \mathrm{g}$ arms only). Table S4. Outcome of tests on proportional hazards between treatments. Table S5. Analysis of time to first CID by selected eosinophil cut-offs (pooled analysis; 3-month data). Table S6. Analysis of time to first CID by selected eosinophil cut-offs (pooled analysis; 6-month data). Figure S1. Summary of CID events by subgroup and by study: a) patient demographics; b) disease history and c) lung function. Figure S2. Forest plot indicating treatment effect of budesonide (BUD) added to formoterol (FORM) on individual components of CID by study, a) full study duration, b) 6 months and c) 3 months. Figure S3. Hazard ratios (HRs) by eosinophil cut-off in pooled analysis of SUN, SHINE and US3 for a) CID, b) exacerbations, c) FEV 1 and d) SGRQ. Figure S4. Effect size by eosinophil cut-off in pooled analysis of SUN, SHINE and US3 for a) 6 months and b)

3 months. Figure S5. Proportion of patients with CID events, by study.

Figure S6. Forest plot for rate ratio for CID and individual components, by study. Figure S7. Risk ratios by eosinophil cut-off in pooled analysis of SUN, SHINE and US3.

\section{Abbreviations}

BCSS: Breathlessness, Cough and Sputum Scale; BUD/FORM: Budesonide/ Formoterol; CID: Clinically Important Deteriorations; COPD: Chronic Obstructive Pulmonary Disease; DPI: Dry Powder Inhaler; FEV 1 : Forced Expiratory Volume in one second; HR: Hazard Ratios; ICS: Inhaled Corticosteroids; LABA: Long-Acting $\beta_{2}$-Agonist; LAMA: Long-Acting Muscarinic Antagonists; pMDI: Pressurized Metered Dose Inhaler; QoL: Quality of Life; RR: Rate Ratio; SGRQ: St George's Respiratory Questionnaire

\section{Acknowledgements}

Dave Singh is supported by the National Institute for Health Research (NIHR) Manchester Biomedical Research Centre (BRC).

The authors would like to thank Stefan Courtney and Amy Evans of inScience Communications, Springer Healthcare Ltd., UK, for providing medical writing support, which was funded by AstraZeneca in accordance with Good Publication Practice (GPP3) guidelines (http://www.ismpp.org/gpp3). 


\section{Authors' contributions}

$\mathrm{MB}$, DS and CJ contributed to the study concept and design, data interpretation and review and final approval of the manuscript. SP contributed to data interpretation and review and final approval of the manuscript. TB contributed to the statistical analysis, data interpretation and review and final approval of the manuscript. PW contributed to the study concept and design, data interpretation and review and final approval of the manuscript. MF contributed to the study concept and design, data preparation, data interpretation and review and final approval of the manuscript.

\section{Funding}

AstraZeneca funded the study and had a role in study design, data collection, data analysis, data interpretation, and writing of the report. The corresponding author had full access to all the data and had final responsibility to submit for publication.

\section{Availability of data and materials}

Data underlying the findings described in this manuscript may be obtained in accordance with AstraZeneca's data sharing policy described at https:// astrazenecagrouptrials.pharmacm.com/ST/Submission/Disclosure.

\section{Ethics approval and consent to participate}

Not applicable.

\section{Consent for publication}

Not applicable.

\section{Competing interests}

$M B$ has received honoraria and travel expenses from AstraZeneca, Boehringer Ingelheim, Chiesi and GlaxoSmithKline. DS has received personal fees from AstraZeneca, Boehringer Ingelheim, Chiesi, Cipla, Genentech, GlaxoSmithKline, Glenmark, Menarini, Mundipharma, Novartis, Peptinnovate, Pfizer, Pulmatrix, Theravance and Verona. CRJ has received speaking and advisory fees and fees for attending advisory boards for AstraZeneca, Boehringer Ingelheim, GlaxoSmithKline, Novartis, Menarini, Mundipharma and Sanofi Regeneron. SP and TB are employees of StatMind, which received funding from AstraZeneca to complete the statistical analyses. PW and MF are full-time employees of AstraZeneca.

\section{Author details}

'Respiratory Medicine Unit, Nuffield Department of Medicine, University of Oxford, Old Road Campus, Oxford OX3 7LF, UK. ${ }^{2}$ Medicines Evaluation Unit, Manchester University NHS Foundation Trust, University of Manchester, Manchester, UK. ${ }^{3}$ The George Institute for Global Health, University of New South Wales, Sydney, Australia. ${ }^{4}$ StatMind, Lund, Sweden. ${ }^{5}$ AstraZeneca, Gothenburg, Sweden.

Received: 26 November 2019 Accepted: 5 January 2020 Published online: 10 January 2020

\section{References}

1. Singh D, Maleki-Yazdi MR, Tombs L, lqbal A, Fahy WA, Naya I. Prevention of clinically important deteriorations in COPD with umeclidinium/vilanterol. Int J COPD. 2016;11:1413-24.

2. Naya IP, Tombs L, Muellerova $H$, Compton C, Jones PW. Long-term outcomes following first short-term clinically important deterioration in COPD. Respir Res. 2018;19:222.

3. Anzueto AR, Vogelmeier CF, Kostikas K, Mezzi K, Fucile S, Bader G, Shen S, Banerji D, Fogel R. The effect of indacaterol/glycopyrronium versus tiotropium or salmeterol/fluticasone on the prevention of clinically important deterioration in COPD. Int J COPD. 2017;12:1325-37.

4. Maleki-Yazdi MR, Singh D, Anzueto A, Tombs L, Fahy WA, Naya I. Assessing short-term deterioration in maintenance-naive patients with COPD receiving umeclidinium/vilanterol and tiotropium: a pooled analysis of three randomized trials. Adv Ther. 2017;33:2188-99.

5. Naya I, Driessen MT, Paly V, Gunsoy N, Risebrough N, Briggs A, Ismaila AS. Long-term consequences of clinically important deterioration in patients with chronic obstructive pulmonary disease treated with twice-daily inhaled corticosteroid/long-acting beta 2 -agonist therapy: results from the $\mathrm{TORCH}$ study. Am J Respir Crit Care Med. 2018;197:A3042.
6. Singh D, D'Urzo AD, Chuecos F, Munoz A, Garcia Gil E. Reduction in clinically important deterioration in chronic obstructive pulmonary disease with aclidinium/formoterol. Respir Res. 2017;18:106.

7. Bafadhel M, Peterson S, De Blas MA, Calverley PM, Rennard SI, Richter K, Fageras M. Predictors of exacerbation risk and response to budesonide in patients with chronic obstructive pulmonary disease: a post-hoc analysis of three randomised trials. Lancet Respir Med. 2018;6:117-26.

8. Ferguson GT, Rabe KF, Martinez FJ, Fabbri LM, Wang C, Ichinose M, Bourne E, Ballal S, Darken P, DeAngelis K, et al. Triple therapy with budesonide/ glycopyrrolate/formoterol fumarate with co-suspension delivery technology versus dual therapies in chronic obstructive pulmonary disease (KRONOS): a double-blind, parallel-group, multicentre, phase 3 randomised controlled trial. Lancet Respir Med. 2018;6:747-58.

9. Rennard SI, Tashkin DP, McElhattan J, Goldman M, Ramachandran S, Martin UJ, Silkoff PE. Efficacy and tolerability of budesonide/formoterol in one hydrofluoroalkane pressurized metered-dose inhaler in patients with chronic obstructive pulmonary disease: results from a 1-year randomized controlled clinical trial. Drugs. 2009;69:549-65.

10. Tashkin DP, Rennard SI, Martin P, Ramachandran S, Martin UJ, Silkoff PE, Goldman M. Efficacy and safety of budesonide and formoterol in one pressurized metered-dose inhaler in patients with moderate to very severe chronic obstructive pulmonary disease: results of a 6-month randomized clinical trial. Drugs. 2008;68:1975-2000.

11. Sharafkhaneh A, Southard JG, Goldman M, Uryniak T, Martin UJ. Effect of budesonide/formoterol pMDI on COPD exacerbations: a double-blind, randomized study. Respir Med. 2012;106:257-68.

12. Ferguson GT, Tashkin DP, Skarby T, Jorup C, Sandin K, Greenwood M, Pemberton K, Trudo F. Effect of budesonide/formoterol pressurized metered-dose inhaler on exacerbations versus formoterol in chronic obstructive pulmonary disease: the 6-month, randomized RISE (revealing the impact of Symbicort in reducing exacerbations in COPD) study. Respir Med. 2017;132:31-41.

13. Martin AL, Marvel J, Fahrbach K, Cadarette SM, Wilcox TK, Donohue JF. The association of lung function and St. George's respiratory questionnaire with exacerbations in COPD: a systematic literature review and regression analysis. Respir Res. 2016;17:40.

14. Lipson DA, Barnhart F, Brealey N, Brooks J, Criner GJ, Day NC, Dransfield MT, Halpin DMG, Han MK, Jones CE, et al. Once-daily single-inhaler triple versus dual therapy in patients with COPD. N Engl J Med. 2018;378:1671-80.

15. Global Initiative for Chronic Obstructive Lung Disease (GOLD): Global strategy for the diagnosis, management, and prevention of chronic obstructive pulmonary disease. Updated 2019.

16. Anzueto AR, Kostikas K, Mezzi K, Shen S, Larbig M, Patalano F, Fogel R, Banerji D, Wedzicha JA. Indacaterol/glycopyrronium versus salmeterol/ fluticasone in the prevention of clinically important deterioration in COPD: results from the FLAME study. Respir Res. 2018;19:121.

\section{Publisher's Note}

Springer Nature remains neutral with regard to jurisdictional claims in published maps and institutional affiliations.

Ready to submit your research? Choose BMC and benefit from:

- fast, convenient online submission

- thorough peer review by experienced researchers in your field

- rapid publication on acceptance

- support for research data, including large and complex data types

- gold Open Access which fosters wider collaboration and increased citations

- maximum visibility for your research: over $100 \mathrm{M}$ website views per year

At $\mathrm{BMC}$, research is always in progress.

Learn more biomedcentral.com/submissions 